\title{
CÂNCER GÁSTRICO APÓS GASTROPLASTIA PARA OBESIDADE MÓRBIDA
}

\section{GASTRIC CANCER AFTER GASTROPLASTY FOR MORBID OBESITY}

\author{
Álvaro Queiroz de Godoy, TCBC-PR ${ }^{1}$; André Reichert da Silva Godoy²; \\ Giselle Reichert da Silva Godoy ${ }^{3}$
}

\section{INTRODUÇÃO}

Há aproximadamente 40 anos tem sido realizado o tratamento cirúrgico da obesidade com ênfase na última década.

Na técnica de Fobi-Capella a redução do reservatório gástrico e criação do "pouch" trazem certa dificuldade de acesso ao estômago remanescente.

Várias complicações têm sido consideradas tais como sangramento, úlcera perfurada e câncer ${ }^{1}$.

Este artigo apresenta o caso de uma paciente que desenvolveu câncer no remanescente gástrico cinco anos após a gastroplastia.

\section{RELATO DO CASO}

Paciente do sexo feminino, 47 anos, há cinco anos foi submetida à gastroplastia tipo Fobi-Capella e há três anos submeteu-se à colecistectomia por videolaparoscopia.

Relatou que há três meses apresentou dor abdominal epigástrica com irradiação para região lombar acompanhada de emagrecimento. Foi submetida a vários exames complementares tais como endoscopia digestiva alta (três vezes), ultrassonografia e investigação laboratorial além de avaliações ortopédica e urológica.

A dor apresentou caráter progressivo atingindo grande intensidade e tornando-se quase incontrolável com analgésicos comuns tendo a paciente sido avaliada por Anestesiologista para analgesia. Subitamente houve aparecimento de icterícia tendo a colangiorressonância magnética evidenciado obstrução do colédoco distal possivelmente provocada por litíase ou estenose cicatricial. A paciente foi encaminhada para tratamento o cirúrgico quando se constatou a presença de extensa lesão tumoral no antro gástrico que invadia o pâncreas, o colédoco e o hilo hepático. Pela grande distensão gástrica havia sinais de sofrimento de sua parede. Como praticamente únicas alternativas no momento, realizouse gastrostomia a Witzel, drenagem biliar externa, biópsia tumoral (adenocarcinoma) e drenagem da cavidade peritonial.

Após plena recuperação foi iniciado quimioterapia. Dois meses após a operação houve aparecimento de quadro séptico de origem pulmonar, que cedeu não às tentativas de tratamento e a paciente evoluiu para óbito.

\section{DISCUSSÃO}

Para o tratamento cirúrgico da obesidade mórbida várias técnicas têm sido empregadas entre as quais a mais frequiente é a gastroplastia de Fobi-Capella já com grandes casuísticas apresentadas².

As complicações precoces desta operação são: infecção de parede, tromboembolismo e hemorragia digestiva. Como complicações tardias podemos citar: vômitos, hérnias incisionais, obstrução da bolsa gástrica, gastrite, esofagite e anemia $^{3}$.

Existe ainda a possibilidade, embora remota, do aparecimento de lesões neoplásicas tanto na bolsa como no estômago remanescente ${ }^{3,4}$. Poucos relatos têm sido encontrados na literatura pertinente justamente em conseqüência da sua raridade.

É importante Assinalar que após este tipo de operação há grande dificuldade para se acessar o remanescente gástrico endoscopicamente ${ }^{4}$, este acesso pode ser conseguido empregando-se, um colonoscópio pediátrico ou enteroscópio de duplo balão, pela alça biliopancreática do "Y de Roux" em casos de alças mais curtas ou mesmo mais longas ${ }^{4}$. Outra maneira seria através de gastrostomias prévias executadas concomitantemente com a gastroplastia. Radiologicamente o estudo do remanescente gástrico poderá ser feito através da injeção de contraste por punção direta do próprio órgão. A presença de metaplasia intestinal antral encontrada no caso apresentado pode ser detectada em 9 a $13 \%$ dos pacientes durante a endoscopia pré-operatória e exige uma acurada avaliação antes da operação ${ }^{5}$.

No presente caso o diagnóstico de câncer foi realizado cinco anos depois da operação. Quando ocorre com menos de cinco anos alguns autores admitem a hipótese de doença previamente existente. Os procedimentos habitualmente empregados para o estudo dos sintomas digestivos como endoscopia, ultrassonografia, exames laboratoriais e tomografia computadorizada normalmente não permitem o diagnóstico. Considerando que o remanescente gástrico, por estar fora do trânsito, oferece dificuldade para acesso propedêutico, uma alternativa interessante é a realização de gastrostomia com marcação radiopaca para permitir endoscopias e ultrassonografias endoscópicas pós-operató-

1. Cirurgião do Aparelho Digestivo do Hospital Evangélico, Hospital Mater Dei, Santa Casa de Misericórdia e Gastrocentro de Londrina - PR

2. Médico Residente de Cirurgia Geral - Hospital das Clínicas da Universidade Federal do Paraná

3. Acadêmica do Curso de Medicina da Pontifícia Universidade Católica do Paraná. 
rias $^{2}$. Considerando também que a incidência de metaplasia intestinal no antro do remanescente gira em torno de $13 \%$ e que a sua relação com tumores já está bem estabelecida al- guns autores têm proposto a gastrectomia junto com gastroplastia ${ }^{5}$. No presente caso a demora no diagnóstico foi decisiva para agravar o prognóstico.

\begin{abstract}
We report a case of patient in whom a gastric remnant cancer developed about five years after a gastric bypass for morbid obesity. We review the literature on gastric cancer after gastroplasty. Access of gastric remnant after gastroplasty (FobiCapella) prevents evaluation and treatment of its disorders (Rev. Col. Bras. Cir. 2007; 34(4): 279-280).
\end{abstract}

Key words: Obesity, morbid; Bariatric surgery; Gastroplasty; Stomach neoplasms.

\section{REFERÊNCIAS}

1. Lord RV, Edwards PD, Coleman MJ. Gastric cancer in the bypassed segment after operation for morbid obesity. Aust N Z J Surg. 1997; 67(8):580-2.

2. Garrido AB. Cirurgia da obesidade. São Paulo: Atheneu; 2002.

3. Zirak C, Lemaitre J, Lebrun E, Journé S, Carlier P. Adenocarcinoma of the pouch after silastic ring vertical gastroplasty. Obes Surg. 2002; 12(5):693-4.

4. Raijman I, Strother SV, Donegan WL. Gastric cancer after gastric bypass for obesity. Case report. J Clin Gastroenterol. 1999; 13(2):191-4.
5. Voellinger DC, Inabnet WB. Laparoscopic Roux-en-Y gastric bypass with remnant gastrectomy for focal intestinal metaplasia of the gastric antrum. Obes Surg. 2002; 12(5):695-8.

Como citar este artigo:

Godoy AQ, Godoy ARS, Godoy GRS. Câncer gástrico após gastroplastia para obesidade mórbida. Rev Col Bras Cir. 2007; 34(4). Disponível em URL: www.scielo.br/rcbc

Endereço para correspondência:

Dr. Álvaro Queiroz de Godoy

Av. Bandeirantes, 324

86010-020 - Londrina - PR 